\title{
Clinical Study on the Medical Value of Combination Therapy Involving Adoptive Immunotherapy and Chemotherapy for Stage IV Colorectal Cancer (COMVI Study)
}

\author{
YOICHIRO YOSHIDA ${ }^{1}$, MASAYASU NAITO $^{1}$, TEPPEI YAMADA ${ }^{1}$, NAOYA AISU $^{1}$, DAIBO KOJIMA ${ }^{1}$, \\ TOSHIYUKI MERA ${ }^{1}$, TOSHIHIRO TANAKA ${ }^{2}$, KEIKO NAITO $^{3}$, KOSEI YASUMOTO ${ }^{3}$, TAKASHI KAMIGAKI ${ }^{3}$, \\ SHIGENORI GOTOH ${ }^{3}$, SHOHTA KODAMA $^{4}$, YUICHI YAMASHITA ${ }^{1}$ and SUGURU HASEGAWA ${ }^{1}$ \\ ${ }^{1}$ Department of Gastroenterological Surgery, ${ }^{2}$ Division of Oncology, Hematology and Infectious Diseases, \\ Department of Internal Medicine, and ${ }^{4}$ Department of Regenerative Medicine \& Transplantation, \\ Fukuoka University Faculty of Medicine, Fukuoka, Japan; \\ ${ }^{3}$ Seta Clinic Group, Tokyo, Japan
}

\begin{abstract}
Background: Adoptive immunotherapy for cancer has evolved through development of novel technologies for generating a large number of activated killer cells, such as $\alpha \beta$ $T$-cells, $\gamma \delta$ T-cells, and natural killer cells. There has been no prospective trial of combination therapy involving adoptive immunotherapy and first-line chemotherapy for stage IV colorectal cancer. The present pilot study aimed to evaluate the safety and feasibility of combination therapy involving adoptive immunotherapy and chemotherapy for stage IV colorectal cancer (COMVI study). Patients and Methods: The COMVI study was a prospective, single-arm pilot trial. Therapy in each 21-day treatment cycle involved XELOX $\left(130 \mathrm{mg} / \mathrm{m}^{2}\right.$ of oxaliplatin on day 1 plus $1,000 \mathrm{mg} / \mathrm{m}^{2}$ of capecitabine twice daily on days 1-14), bevacizumab (7.5 $\mathrm{mg} / \mathrm{kg}$ on day 1), and $\alpha \beta$ T-lymphocytes (over $5 \times 10^{9}$ on day 18) cultured ex vivo with an immobilized antibody to $C D 3$ and interleukin-2. Results: The study included six patients (two men and four women) between June 2013 and September 2014. The median patient age was 68 years (range $=55-75$ years). The overall response rate was $83.3 \%$ [complete response in two (33.3\%); partial response in three (50.0\%); stable disease in one (16.7\%); no cases of progressive disease]. The tumor volume reduction rate was $53 \%$ (range $=38.0-100 \%$ ). The median progression-free and overall survival durations were 567 and 966 days, respectively. Most adverse events were mild-to-moderate in
\end{abstract}

Correspondence to: Yoichiro Yoshida, Department of Gastroenterological Surgery, Fukuoka University Faculty of Medicine, 7-45-1 Nanakuma, Jonan-ku, Fukuoka 814-0180, Japan. Tel: +81 928011011, Fax: +81 928639759, e-mail: yy4160@yahoo.co.jp

Key Words: Colorectal cancer, chemotherapy, immunotherapy, XELOX, $\alpha \beta T$, bevacizumab. intensity, and no grade 4 adverse events occurred in the six patients. Only one patient experienced grade 3 hypertension and ileus. Immunotherapy-associated toxicity was minimal in this study. Conclusion: Combination therapy involving adoptive immunotherapy and chemotherapy for stage IV colorectal cancer is feasible and safe. Phase II prospective studies are needed to confirm the safety and efficacy of such chemoimmunotherapy.

Until recently, it has been commonly believed that chemotherapy and immunotherapy should not be combined because of the myelosuppressive effect of most cytotoxic agents. However, it was recently shown that chemotherapeutics can exhibit several beneficial effects on the immune system (1). A previous study showed that 5fluorouracil (5-FU) can up-regulate tumor antigen expression in colorectal and breast cancer cells (2). Furthermore, suppressive regulatory T-cells were found to be depleted by several chemotherapeutics, resulting in enhanced T-cell reactivity $(3,4)$. Oxaliplatin induces the immunogenic death of colorectal cancer (CRC) cells, and this effect determines its therapeutic efficacy in patients with CRC (5). Additionally, antibodies to vascular endothelial growth factor (VEGF) can enhance the antitumor activity of adoptively transferred antitumor T-cells (6).

Immunotherapy represents a major breakthrough in cancer therapy in recent years. Programmed death 1 (PD1) is a key immune-checkpoint receptor expressed by activated T-cells. The use of antibodies to PD1 and programmed death-ligand 1 (PDL1) appears to be one of the most promising immunotherapy approaches $(7,8)$. PD1 is an inhibitory receptor and plays an important role in the regulation of Tcells. Therefore, T-cells were reconfirmed to play an important role in cancer treatment. 
Improvement of outcomes in primary treatment may require a novel therapeutic strategy. The clinical development of cancer immunotherapy historically avoided front-line combination with chemotherapy based on the assumption that cytotoxic agents and corticosteroids might affect induced immunity (9). However, the findings of previous studies provide a rationale for the combination of chemotherapy and immunotherapy. To our knowledge, there has been no prospective trial of combination therapy involving adoptive immunotherapy and first-line chemotherapy for stage IV CRC. Therefore, this pilot study aimed to evaluate the safety and feasibility of combination therapy involving $\alpha \beta$ T-cell therapy with capecitabine and oxaliplatin (XELOX) and bevacizumab for stage IV CRC (COMVI study).

\section{Patients and Methods}

Study design. The COMVI study was designed as a prospective, open-label, nonrandomized, and single-arm clinical trial in Japan. This study was performed in accordance with the ethical guidelines for clinical studies. The Institutional Review Board at Fukuoka University approved the protocol, and the study has been registered with the University Hospital Medical Information Network Clinical Trials Registry (ID: UMIN000010908).

The study evaluated the safety and feasibility of combination therapy involving adoptive immunotherapy and chemotherapy for advanced or recurrent stage IV CRC. The primary endpoint was safety. The secondary endpoints were the objective tumor response rate and progression-free survival. The target sample size was six patients. Because this was a feasibility study, the sample size was not calculated.

Eligibility criteria. Six patients were enrolled in this study between June 2013 and September 2014. Eligible patients were $\geq 20$ years of age, had histologically confirmed CRC without prior chemotherapy for metastatic disease, and had completed any adjuvant therapy at least 6 months previously. Additionally, they met the following criteria: Eastern Cooperative Oncology Group performance status (ECOG PS), 0-2; life expectancy, $\geq 12$ weeks; white blood cell count, $\geq 3,000 / \mathrm{mm}^{3}$; neutrophil count, $\geq 1,500 / \mathrm{mm}^{3}$; platelet count, $\geq 75,000 / \mathrm{mm}^{3}$; hemoglobin, $\geq 8.5 \mathrm{~g} / \mathrm{dl}$; total bilirubin, $\leq 2.0$ times the upper limit of normal; aspartate aminotransferase and alanine aminotransferase, $\leq 3.0$ times the upper limit of normal; serum creatinine, $\leq 2.0 \mathrm{mg} / \mathrm{dl}$. The Institutional Review Boards of all participating institutions approved the clinical study, and written informed consent was obtained from each patient.

Patients who met the following criteria were excluded: interstitial lung disease, autoimmune disease, clinically significant cardiovascular disease, active infection, history of serious hypersensitivity to drugs, systemic steroid administration, pregnant women, multiple primary cancers within the previous 5 years, positive human immunodeficiency virus test result or human T-cell lymphotropic virus type I test result, and any other conditions that made the patient unsuitable for this study.

Treatment. The patients received XELOX plus bevacizumab therapy $(7.5 \mathrm{mg} / \mathrm{kg}$ of bevacizumab and $130 \mathrm{mg} / \mathrm{m} 2$ of oxaliplatin on day 1 plus $1,000 \mathrm{mg} / \mathrm{m}^{2}$ of capecitabine twice daily on days $1-14$, every 3 weeks) for advanced or recurrent CRC (Figure 1) (10,11). Dose reductions of capecitabine and oxaliplatin were required for all grade 3 or 4 toxicities attributable to the study medications. The dose of bevacizumab was not reduced. The treatment was continued until disease progression, unacceptable toxicity, or withdrawal of consent. Treatment was delayed if any of the following criteria were noted on the day when administration was scheduled or on the previous day: neutrophil count $<1,000 / \mathrm{mm}^{3}$, platelet count $<75,000 / \mathrm{mm}^{3}$, active infection with fever $\geq 38.0^{\circ} \mathrm{C}$, grade 2 or worse peripheral sensory neuropathy, and other grade 2 or worse non-hematological toxicitty. The oxaliplatin dose was reduced to $100 \mathrm{mg} / \mathrm{m}^{2}$ if grade $3-4$ neutropenia or thrombocytopenia, persistent grade 2 or reversible grade 3 PSN, or any grade 3-4 non-hematological toxicity occurred. The study was terminated if grade 3 toxicity persisted after a 21-day washout period or if grade $4 \mathrm{PSN}$ or a grade 2-4 allergic reaction occurred. Additionally, the study was terminated if the patient required more than 3 weeks to recover from any adverse event.

Peripheral blood mononuclear cells were harvested using centrifugation. Over $1 \times 10^{6}$ harvested cells were cultured with an immobilized antibody to CD3 and interleukin (IL)-2 for 14 days, and over $5 \times 10^{9}$ lymphocytes were obtained on average. The cultured lymphocytes included $61 \pm 15 \%$ of $\mathrm{CD}^{+} \mathrm{T}$-cells, $30 \pm 15 \%$ of $\mathrm{CD}^{+}$ T-cells (CD4+: ${ }^{+} 8^{+}$ratio, 0.8 on average), and a small percentage of natural killer (NK) cells and $\mathrm{NK}$ T-cells, indicating that the proliferation of $\mathrm{CD} 8^{+} \mathrm{T}$-lymphocytes was much greater than that of CD4+ T-lymphocytes during the 2-week culture period $(12,13)$. Over $5 \times 10^{9} \alpha \beta$ T-lymphocytes cultured ex vivo with an immobilized antibody to CD3 and IL2 were injected intravenously into patients once every 3 weeks for 4.5 months (six cycles) or longer.

Evaluation of chemotherapy. All patients underwent a physical examination, chest radiography, and computed tomographic scans of the abdomen, pelvis, and chest before starting treatment (baseline). All patients were included in the safety and efficacy analyses. The severity of adverse effects was evaluated according to the National Cancer Institute Common Toxicity Criteria (NCICTC), version 4.0 (14). Tumors were measured at 6- to 8-week intervals, and responses were evaluated according to the response evaluation criteria for solid tumors (RECIST), version 1.1 (15). The evaluation of responses was based on radiologist-reported measurements. Complete and partial responses required subsequent confirmation of the responses after an interval of at least 4 weeks.

\section{Results}

Baseline patient characteristics. Six patients were enrolled in this study between June 2013 and September 2014. The characteristics of the study patients are shown in Table I. The median patient age was 68 (range $=55-75$ ) years, and four out of the six patients were female. ECOG PS was 0 for all patients.

Treatment. XELOX plus bevacizumab: The median number of treatment cycles was 14.5 (range=4-23). Of the six patients, five $(83.3 \%)$ continued treatment through six cycles, while one $(16.7 \%)$ discontinued treatment because of an adverse event (malaise, grade 1). 

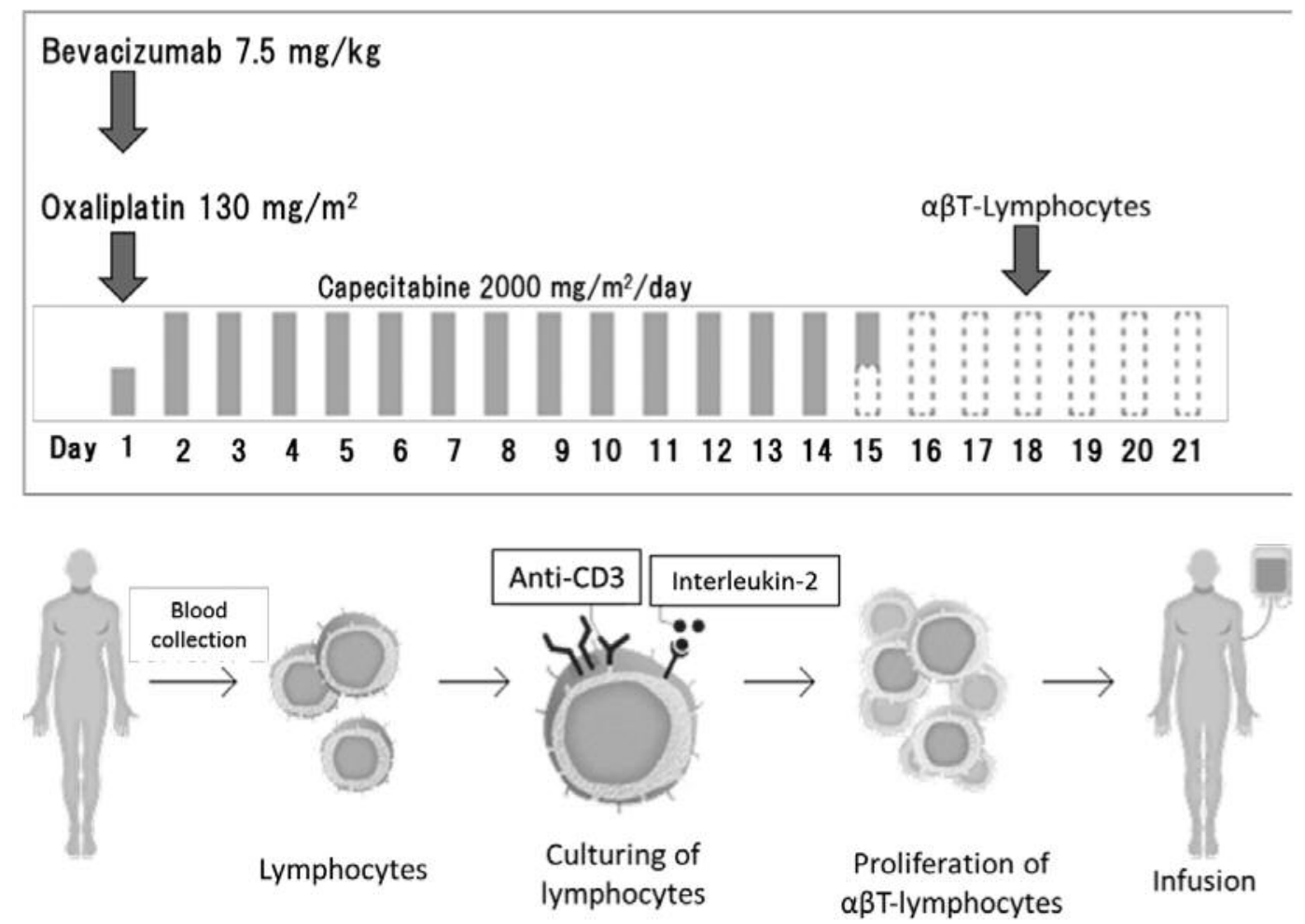

Figure 1. Chemoimmunotherapy approach. Patients received capecitabine and oxaliplatin plus bevacizumab and $\alpha \beta$ T-lymphocyte therapy.

Table I. Baseline patient characteristics.

\begin{tabular}{lccccc}
\hline Case & Age, years & Gender & Primary site & Metastatic site & KRAS status \\
\hline 1 & 70 & $\mathrm{~F}$ & Sigmoid colon & Peritoneum (synchronous) & Wild-type \\
2 & 70 & $\mathrm{~F}$ & Cecum & Liver (synchronous) & G13D \\
3 & 56 & $\mathrm{~F}$ & Transverse colon & Piver (metachronous) & Wild-type \\
4 & 66 & $\mathrm{~F}$ & Cecum & Becitoneum (synchronous) & G13D \\
5 & 55 & $\mathrm{M}$ & Bone marrow, lymph node (synchronous) & Wild-type \\
6 & 75 & $\mathrm{M}$ & Ascending colon & Liver (synchronous) & Wild-type \\
\hline
\end{tabular}

F: Female, M: male, KRAS: v-Ki-ras2 Kirsten rat sarcoma viral oncogene homolog.

$\alpha \beta$ T-Lymphocytes: The median number of treatment cycles was 11.5 (range=6-21). The mean number of cells for each infusion was $5.98 \times 10^{9}\left(\right.$ range $\left.=4.5-7.9 \times 10^{9}\right)($ Table II $)$. All patients continued treatment for at least six cycles.

Treatment was delayed at four cycles in one patient because of ileus. However, the patient resumed chemotherapy because ileus was cured with conservative treatment. No patient required dose reduction before six cycles.

Efficacy. The confirmed response rate was $83.3 \%$ [complete response $=2 / 6(33.3 \%)$; partial response $=3 / 6(50.0 \%)$; stable disease $=1 / 6(16.7 \%)$; progressive disease $=0 \%$, for a disease control rate of $100 \%$. The median progression-free and overall survival durations were 567 and 966 days, respectively (Figure 2).

Safety. Adverse events in the six patients are summarized in Table III. Grade 3 or higher hemotoxicity did not occur in any patient, and only one patient $(16.7 \%)$ developed a grade 3 non-hematological toxicity (hypertension). There were no other severe treatment-related adverse events and no treatment-related death. 
Table II. $\alpha \beta$ T-Lymphocyte infusion (cell number $\times 10^{9}$ ).

\begin{tabular}{lccccccc}
\hline & \multicolumn{7}{c}{ Cycle } \\
\cline { 2 - 6 } Case & 1 & 2 & 3 & 4 & 5 & 6 & Average \\
\hline 1 & 5.2 & 6.4 & 7.0 & 5.1 & 5.0 & 6.4 & 5.85 \\
2 & 7.6 & 5.4 & 4.5 & 6.1 & 4.7 & 6.2 & 5.75 \\
3 & 6.5 & 5.6 & 5.4 & 6.3 & 7.7 & 7.9 & 6.57 \\
4 & 5.0 & 6.1 & 5.2 & 5.6 & 5.6 & 6.6 & 5.68 \\
5 & 5.8 & 6.1 & 6.3 & 5.1 & 6.4 & 5.2 & 5.81 \\
6 & 5.1 & 6.8 & 5.4 & 5.4 & 7.6 & 6.9 & 6.20 \\
\hline
\end{tabular}

\section{Discussion}

Adoptive immunotherapy of cancer has evolved through the development of novel techniques for generating large numbers of activated killer cells, such as $\alpha \beta$ T-cells, $\gamma \delta \mathrm{T}$ cells, and NK cells. Due to advances in technology, these killer cells have become available for adoptive immunotherapy as ex vivo-expanded killer cells. Ex vivoexpanded $\alpha \beta$ T-cells have been studied since the 1980s (16) and have been used to treat cancer such as hepatocellular carcinoma (17) and lung cancer (18).

The relation between chemotherapy and immunity has been reported. Maeda et al. reported that FOLFOX not only induced direct cytotoxicity against cancer cells, but also enhanced antitumor immunity owing to regulatory T-cell (Treg) depletion (19). Previous clinical reports have shown that subcutaneous granulocyte macrophage colonystimulating factor and IL2 induced potent immunological and antitumor activity in patients with metastatic colon cancer when combined with chemotherapy (20). Increased lymphocyte and eosinophil counts, amplification in central memory, significant depletion of immunosuppressive Tregs, and activation of colon cancer-specific cytotoxic T-cells were observed. Thus, it may be appropriate to combine FOLFOX chemotherapy with immunotherapy. However, grade 3/4 neutropenia and febrile neutropenia were shown to be greater with FOLFOX than with XELOX (21). If treatment cannot be performed as planned, it will be impossible to combine chemotherapy and immunotherapy $(11,21)$. Therefore, we used XELOX, which might be as effective as FOLFOX. As expected, it was possible to safely perform the treatment without grade 3 or higher hematological toxicity in this study.

Tumor-infiltrating T-cells in CRC have been reported to inhibit tumor growth and be associated with improved prognosis $(22,23)$. Although adoptive activated Tlymphocyte immunotherapy is mainly a non-specific therapy without in vitro sensitization by cancer-specific antigen peptides, the possibility of specific killer T-cells existing and
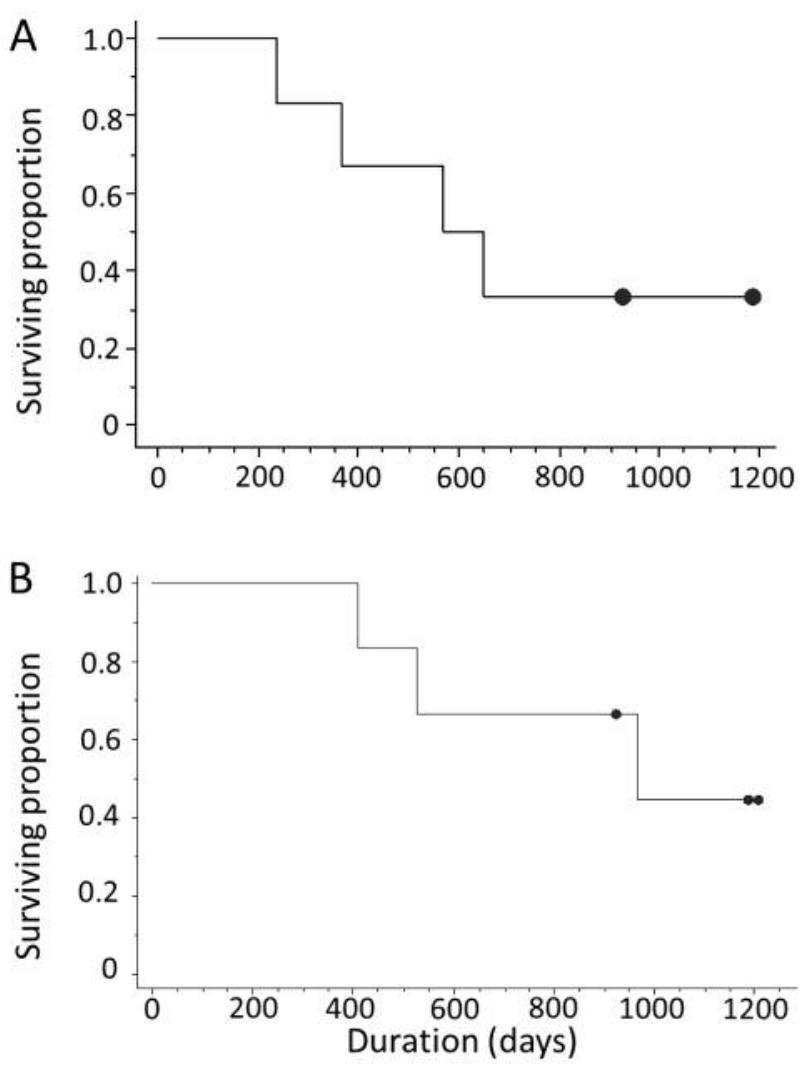

Figure 2. Kaplan-Meier survival curve showing progression-free (A) and overall (B) survival.

their population expanding during the 2-week culture process cannot be excluded.

Although CRC can appear to be eradicated with chemotherapy and radiotherapy, small cancer stem cell fractions capable of self-propagating and sustaining tumor growth frequently persist and lead to recurrence and treatment failure. Such cells are often resistant to various treatments, including chemotherapy and radiotherapy, immunotherapy may, however, still be effective (24-26). One patient with disseminated carcinomatosis of the bone marrow (DCBM) was included in this study. DCBM is often also associated with disseminated intravascular coagulation, and both are associated with extremely poor prognosis (27). Although the patients with DCBM affected the results, good outcomes were obtained even with consideration of the influence. Furthermore, synchronous metastases have been reported to confer a poor prognosis (28-30), and five out of the six patients in this study had synchronous metastases. The results might have been biased because of the small number of patients in this clinical trial.

The limits of surgery and chemotherapy for treating patients with CRC support the development of novel treatment 
Table III. Adverse events during chemoimmunotherapy.

\begin{tabular}{lcc}
\hline Case & Hematological & Non-hematological \\
\hline 1 & Thrombocytopenia: G2 & Insomnia: G1, anorexia: G1, PN: G1 \\
2 & Anemia: G2, thrombocytopenia: G1 & Anorexia: G1, PN: G1, nausea: G1, diarrhea: G2 \\
3 & Thrombocytopenia: G2, WBC: G1 & PN: G1, fever: G1, HFS: G2 \\
4 & WBC: G1, anemia: G2, AST: G1, ALT: G2 & PN: G1, anorexia: G1, vomiting: G1, ileus: G2, hypertension: G3 \\
5 & WBC: G1, AST: G1, ALT: G2 & PN: G1, diarrhea: G1, anorexia: G1, nausea: G1 \\
6 & Anemia: G1 & Malaise: G1 \\
\hline
\end{tabular}

G: Grade, WBC: white blood cell, AST: aspartate transaminase, ALT: alanine transaminase, PN: peripheral neuropathy, HFS: hand-foot syndrome.

approaches. Immunotherapy alone is insufficient for treating metastatic CRC. The results of this trial may lead to the development of combination therapies involving chemotherapy and other immunotherapies that enhance T-cell immune responses, including antibody to cytotoxic T-lymphocyte antigen 4, ipilimumab (31), anti-PD1 (32) and anti-PDL1 (33). Further basic and clinical studies will provide additional clues to the development and establishment of successful immunotherapy approaches with $\alpha \beta$ T-cells.

This study found that chemoimmunotherapy is a safe and feasible treatment option for patients with CRC. However, the low number of patients included restricts the presentation of well-defined conclusions. The results strongly support further studies on the combined use of adoptive immunotherapy and chemotherapy.

\section{Acknowledgements}

The Authors thank the participating patients, their family members, and all researchers involved in this study. The Authors are also grateful to Drs Tetsuo Shinohara and Takafumi Maekawa for their support as the Independent Review Committee.

\section{Conflicts of Interest}

The Authors declare that they have no conflict of interest in regard to this study.

\section{References}

1 Lake RA and Robinson BW: Immunotherapy and chemotherapy - a practical partnership. Nat Rev Cancer 5(5): 397-405, 2005.

2 Correale P, Aquino A, Giuliani A, Pellegrini M, Micheli L, Cusi MG, Nencini C, Petrioli R, Prete S and De Vecchis L: Treatment of colon and breast carcinoma cells with 5-fluorouracil enhances expression of carcinoembryonic antigen and susceptibility to HLA-A (*) 02.01 restricted, CEA-peptide-specific cytotoxic T cells in vitro. Int J Cancer 104(4): 437-445, 2003.

3 Correale P, Cusi MG, Tsang KY, Del Vecchio MT, Marsili S, La Placa M, Intrivici C, Aquino A, Micheli L and Nencini C: Chemoimmunotherapy of metastatic colorectal carcinoma with gemcitabine plus FOLFOX 4 followed by subcutaneous granulocyte macrophage colony-stimulating factor and interleukin-2 induces strong immunologic and antitumor activity in metastatic colon cancer patients. J Clin Oncol 23(35): 8950-8958, 2005.

4 Apetoh L, Ghiringhelli F, Tesniere A, Obeid M, Ortiz C, Criollo A, Mignot G, Maiuri MC, Ullrich E and Saulnier P: Toll-like receptor 4-dependent contribution of the immune system to anticancer chemotherapy and radiotherapy. Nat Med 13(9): 1050-1059, 2007.

5 Tesniere A, Schlemmer F, Boige V, Kepp O, Martins I, Ghiringhelli F, Aymeric L, Michaud M, Apetoh L and Barault L: Immunogenic death of colon cancer cells treated with oxaliplatin. Oncogene 29(4): 482-491, 2010.

6 Shrimali RK, Yu Z, Theoret MR, Chinnasamy D, Restifo NP and Rosenberg SA: Antiangiogenic agents can increase lymphocyte infiltration into tumor and enhance the effectiveness of adoptive immunotherapy of cancer. Cancer Res 70(15): 6171-6180, 2010.

7 Freeman GJ, Long AJ, Iwai Y, Bourque K, Chernova T, Nishimura H, Fitz LJ, Malenkovich N, Okazaki T and Byrne MC: Engagement of the PD-1 immunoinhibitory receptor by a novel B7 family member leads to negative regulation of lymphocyte activation. J Exp Med 192(7): 1027-1034, 2000.

8 Iwai Y, Ishida M, Tanaka Y, Okazaki T, Honjo T and Minato N: Involvement of PD-L1 on tumor cells in the escape from host immune system and tumor immunotherapy by PD-L1 blockade. Proc Natl Acad Sci USA 99(19): 12293-12297, 2002.

9 Braly P, Nicodemus CF, Chu C, Collins Y, Edwards R, Gordon A, McGuire W, Schoonmaker C, Whiteside T, Smith LM and Method M: The Immune adjuvant properties of front-line carboplatin-paclitaxel: a randomized phase 2 study of alternative schedules of intravenous oregovomab chemoimmunotherapy in advanced ovarian cancer. J Immunother 32(1): 54-65, 2009.

10 Yoshida Y, Hoshino S, Aisu N, Naito M, Tanimura S, Mogi A, Tanaka T, Hirata K, Tamura K and Yamashita Y: Administration of chemotherapy via the median cubital vein without implantable central venous access ports: port-free chemotherapy for metastatic colorectal cancer patients. Int J Clin Oncol 20(2): 332-337, 2015.

11 Yoshida Y, Hirata K, Matsuoka H, Iwamoto S, Kotaka M, Fujita H, Aisu N, Hoshino S, Kosaka T, Maeda K, Kiyomi F and Yamashita Y: A single-arm Phase II validation study of preventing oxaliplatin-induced hypersensitivity reactions by dexamethasone: the AVOID trial. Drug Des Devel Ther 9: 60676073,2015

12 Goto S, Noguchi A, Jinguji H and Takahara M: The therapeutic potential of immuno-cell therapy of cancer in combination with aminobisphosphonates. Anticancer Res 26(6a): 3989-3995, 2006. 
13 Yoshida Y, Naito M, Yamada T, Aisu N, Daibo K, Mera T, Tanaka T, Naito K, Yasumoto K, Kamigaki T, Goto S, Yamashita $\mathrm{Y}$ and Hasegawa S: Adoptive chemoimmunotherapy using activated alphabeta $\mathrm{T}$ cells for stage IV colorectal cancer. Anticancer Res 36(7): 3741-3746, 2016.

14 Health UDo and Services H: National Cancer Institute. Common Terminology Criteria for Adverse Events (CTCAE) Version 4.0. US Department of Health and Human Services National Institutes of Health, National Cancer Institute, 2009.

15 Eisenhauer EA, Therasse P, Bogaerts J, Schwartz LH, Sargent D, Ford R, Dancey J, Arbuck S, Gwyther S, Mooney M, Rubinstein L, Shankar L, Dodd L, Kaplan R, Lacombe D and Verweij J: New response evaluation criteria in solid tumours: revised RECIST guideline (version 1.1). Eur J Cancer 45(2): 228-247, 2009.

16 Mule JJ, Shu S, Schwarz SL and Rosenberg SA: Adoptive immunotherapy of established pulmonary metastases with LAK cells and recombinant interleukin-2. Science 225(4669): 14871489, 1984.

17 Takayama T, Sekine T, Makuuchi M, Yamasaki S, Kosuge T, Yamamoto J, Shimada K, Sakamoto M, Hirohashi S, Ohashi Y and Kakizoe T: Adoptive immunotherapy to lower postsurgical recurrence rates of hepatocellular carcinoma: a randomised trial. Lancet 356(9232): 802-807, 2000.

18 Iwai K, Soejima K, Kudoh S, Umezato Y, Kaneko T, Yoshimori K, Tokuda H, Yamaguchi T, Mizoo A, Setoguchi Y, Kamigaki T, Fujimoto $\mathrm{K}$ and Goto S: Extended survival observed in adoptive activated T-lymphocyte immunotherapy for advanced lung cancer: results of a multicenter historical cohort study. Cancer Immunol Immunother 61(10): 1781-1790, 2012.

19 Maeda K, Hazama S, Tokuno K, Kan S, Maeda Y, Watanabe Y, Kamei R, Shindo Y, Maeda N and Yoshimura K: Impact of chemotherapy for colorectal cancer on regulatory $\mathrm{T}$-cells and tumor immunity. Anticancer Res 31(12): 4569-4574, 2011.

20 Correale P, Tagliaferri P, Fioravanti A, Del Vecchio MT, Remondo C, Montagnani F, Rotundo MS, Ginanneschi C, Martellucci I, Francini E, Cusi MG, Tassone P and Francini G: Immunity feedback and clinical outcome in colon cancer patients undergoing chemoimmunotherapy with gemcitabine + FOLFOX followed by subcutaneous granulocyte macrophage colonystimulating factor and aldesleukin (GOLFIG-1 Trial). Clin Cancer Res 14(13): 4192-4199, 2008.

21 Cassidy J, Clarke S, Diaz-Rubio E, Scheithauer W, Figer A, Wong R, Koski S, Lichinitser M, Yang TS, Rivera F, Couture F, Sirzen F and Saltz L: Randomized phase III study of capecitabine plus oxaliplatin compared with fluorouracil/folinic acid plus oxaliplatin as first-line therapy for metastatic colorectal cancer. J Clin Oncol 26(12): 2006-2012, 2008.

22 Diederichsen AC, Hjelmborg JvB, Christensen PB, Zeuthen J and Fenger $\mathrm{C}$ : Prognostic value of the $\mathrm{CD}^{+} / \mathrm{CD}^{+}{ }^{+}$ratio of tumour infiltrating lymphocytes in colorectal cancer and HLADR expression on tumour cells. Cancer Immunol Immunother 52(7): 423-428, 2003.

23 Galon J, Costes A, Sanchez-Cabo F, Kirilovsky A, Mlecnik B, Lagorce-Pagès $\mathrm{C}$, Tosolini $\mathrm{M}$, Camus $\mathrm{M}$, Berger $\mathrm{A}$ and Wind $\mathrm{P}$ : Type, density, and location of immune cells within human colorectal tumors predict clinical outcome. Science 313(5795): 1960-1964, 2006

24 Weng D, Song B, Durfee J, Sugiyama V, Wu Z, Koido S, Calderwood SK and Gong J: Induction of cytotoxic T lymphocytes against ovarian cancer-initiating cells. Int J Cancer 129(8): 19902001, 2011

25 Takahara A, Koido S, Ito M, Nagasaki E, Sagawa Y, Iwamoto T, Komita H, Ochi T, Fujiwara H, Yasukawa M, Mineno J, Shiku $\mathrm{H}$, Nishida S, Sugiyama H, Tajiri H and Homma S: Gemcitabine enhances Wilms' tumor gene WT1 expression and sensitizes human pancreatic cancer cells with WT1-specific T-cellmediated antitumor immune response. Cancer Immunol Immunother 60(9): 1289-1297, 2011.

26 Weng D, Song B, Koido S, Calderwood SK and Gong J: Immunotherapy of radioresistant mammary tumors with early metastasis using molecular chaperone vaccines combined with ionizing radiation. J Immunol 191(2): 755-763, 2013.

27 Naito M, Yoshida Y, Aisu N, Tanimura S, Hoshino S, Tanaka T, Nimura S, Tamura K and Yamashita Y: A report of disseminated carcinomatosis of the bone marrow originating from transverse colon cancer successfully treated with chemotherapy using XELOX plus bevacizumab. Case Rep Oncol 7(2): 426-434, 2014.

28 Tsang WY, Ziogas A, Lin BS, Seery TE, Karnes W, Stamos MJ and Zell JA: Role of primary tumor resection among chemotherapytreated patients with synchronous stage IV colorectal cancer: a survival analysis. J Gastrointest Surg 18(3): 592-598, 2014.

29 Xu H, Xia Z, Jia X, Chen K, Li D, Dai Y, Tao M and Mao Y: Primary tumor resection is associated with improved survival in stage IV colorectal cancer: An instrumental variable analysis. Sci Rep 5: 16516, 2015.

30 Faron M, Pignon JP, Malka D, Bourredjem A, Douillard JY, Adenis A, Elias D, Bouche $\mathrm{O}$ and Ducreux M: Is primary tumour resection associated with survival improvement in patients with colorectal cancer and unresectable synchronous metastases? A pooled analysis of individual data from four randomised trials. Eur J Cancer 51(2): 166-176, 2015.

31 Hodi FS, O'Day SJ, McDermott DF, Weber RW, Sosman JA, Haanen JB, Gonzalez R, Robert C, Schadendorf D, Hassel JC, Akerley W, van den Eertwegh AJ, Lutzky J, Lorigan P, Vaubel JM, Linette GP, Hogg D, Ottensmeier CH, Lebbe C, Peschel C, Quirt I, Clark JI, Wolchok JD, Weber JS, Tian J, Yellin MJ, Nichol GM, Hoos A and Urba WJ: Improved survival with ipilimumab in patients with metastatic melanoma. N Engl J Med 363(8): 711-723, 2010.

32 Topalian SL, Hodi FS, Brahmer JR, Gettinger SN, Smith DC, McDermott DF, Powderly JD, Carvajal RD, Sosman JA, Atkins MB, Leming PD, Spigel DR, Antonia SJ, Horn L, Drake CG, Pardoll DM, Chen L, Sharfman WH, Anders RA, Taube JM, McMiller TL, Xu H, Korman AJ, Jure-Kunkel M, Agrawal S, McDonald D, Kollia GD, Gupta A, Wigginton JM and Sznol M: Safety, activity, and immune correlates of anti-PD-1 antibody in cancer. N Engl J Med 366(26): 2443-2454, 2012.

33 Brahmer JR, Tykodi SS, Chow LQ, Hwu WJ, Topalian SL, Hwu P, Drake CG, Camacho LH, Kauh J, Odunsi K, Pitot HC, Hamid O, Bhatia S, Martins R, Eaton K, Chen S, Salay TM, Alaparthy S, Grosso JF, Korman AJ, Parker SM, Agrawal S, Goldberg SM, Pardoll DM, Gupta A and Wigginton JM: Safety and activity of anti-PD-L1 antibody in patients with advanced cancer. N Engl J Med 366(26): 2455-2465, 2012.

Received May 2, 2017

Revised May 22, 2017

Accepted May 23, 2017 